\title{
Role of Commiphora Mol Mol and Doxycycline in Prophylaxis of Spontaneous Bacterial Peritonitis in Egyptians Cirrhotic Patients
}

\author{
Tarek Mohammed Mostafa, ${ }^{1}$ Osama Mohamed Hassan Ibrahim, ${ }^{1}$ \\ Gamal Ahmed Abd El-Khalek Badra, ${ }^{2}$ Eman Ibrahim Abd El-Kader El-Berri ${ }^{*}$
}

\author{
${ }^{1}$ Department of Clinical Pharmacy, Faculty of Pharmacy, Tanta University, Tanta, Egypt \\ ${ }^{2}$ Department of Hepatology, National Liver Institute, Menofiya University. Shebeen El Kom, Egypt \\ "Corresponding Author \\ Eman Ibrahim Abd El-Kader El-Berri \\ Demonastrator of Clinical Pharmacy \\ Department of Clinical Pharmacy \\ Faculty of Pharmacy \\ Tanta University \\ Tanta, 31527, Egypt. \\ Email: eman.elberri@yahoo.com \\ Mobil: +2001003592593
}

Received: 18 August 2015; | Revised: 27 August 2015; | Accepted: 6 September 2015

\begin{abstract}
Aims: this study aimed to evaluate the role of commiphora mol mol and doxycycline in the prophylaxis of spontaneous bacterial peritonitis in cirrhotic patients. Methodology: sixty ascetic cirrhotic patients from National Liver Institute, Menofiya University (Shebeen El-Kom- Egypt) with a history of at least one previous episode of SBP were included in blinded randomized clinical study. Patients were divided into four groups in a fashion; each group consists of 15 patients. Group one received ciprofloxacin (control group), group two received doxycycline, group three received commiphora mol mol and group four received a combination of commiphora mol mol and doxycycline for six months. Serum interleukin 6 (IL 6) and C Reactive Protein (CRP) level were the primary inflammatory markers of the study to evaluate the effect of the studied medications. Results: both IL-6 and CRP levels showed significant decrease three and six months after treatment in all studied groups $(\mathrm{P}<0.05)$. Group four showed a significant decrease in IL 6 and CRP level compared with other three groups $(\mathrm{P}<0.05)$. Conclusion: the results of the current study strongly support the efficacy of doxycycline and Commiphora molmol as a primary prophylactic therapy in patients with SBP. Furthermore, commiphora mol mol/doxycycline combination was the most effective and showed synergistic effect which may be useful in decrease emergence of resistant strains.
\end{abstract}

Keywords: Spontaneous bacterial peritonitis; Commiphora mol mol; Doxycycline; IL 6; CRP 


\section{Introduction}

Spontaneous bacterial peritonitis (SBP) is a bacterial infection of ascitic fluid which arises in the absence of any other source of sepsis within the peritoneum or adjacent tissues [1]. The Gramnegative bacteria are largely responsible for SBP episodes [2]. Percentage of gram positive bacteria causing SBP represent about $48 \%$ which leading to increase resistance towards quinolones prophylactic therapy [2].

In liver cirrhosis, three mechanisms are proposed for the pathogenesis of SBP [3].Patients with ascetic fluid PMN counts $>250$ cells $/ \mathrm{mm}^{3}$ in a clinical setting, compatible with ascitic fluid infection, should receive empiric antibiotic therapy such as cefotaxime $2 \mathrm{~g}$ intravenously every 8 hours for 5 days or ciprofloxacin $200 \mathrm{mg}$ intravenously every 12 hours for 7 days[4].

After the resolution of an episode of SBP, the recurrence is frequent. Therefore, intestinal decontamination is required by antibiotic prophylaxis which could not only improve short term survival but also could reduce the overall risk of infections including SBP [5]. According to European Association for the Study of the Liver guidelines the administration of prophylactic antibiotics reduces the risk of recurrent SBP, Oral norfloxacin at a dose of 400 $\mathrm{mg}$ daily is the prophylactic therapy of choice. Alternative prophylactic antibiotics include oral ciprofloxacin $750 \mathrm{mg}$ once weekly [6]. Doxycycline exerts a broad range of antimicrobial activity against both gram-positive and gram-negative bacteria that considered predisposing agents for SBP such as Shigella, Klebsiella, Escheria coli, Enterobacter aerogenosa, Uresinia pestis [7] and Brucella [8].

Commiphora molmol, an herbal medicine that has antiseptic and antimicrobial activities was formerly approved in Egypt for management of both Fasciola hepatica and Schistosome infections [9].

The aim of our study was directed to evaluate the role of commiphora mol mol and doxycycline in the prophylaxis of spontaneous bacterial peritonitis in Egyptian cirrhotic patients.

\section{Materials and Methods}

This study design was blinded randomized clinical study that was conducted in the National Liver Institute, Menofiya University (Shebeen ElKom- Egypt) between October 2012 and November 2013. The protocol for this study was approved by the National Research Ethics Committee of Menoufiya University, Shebin El-kom,Egypt with Institutional Review Board (IRB) protocol number 0064/2012. The diagnosis of SBP was confirmed if the ascetic fluid polymorph nuclear cell (PMN) count was greater than $250 \mathrm{~mm}^{3}$ with or without positive culture and by absence of an intra- abdominal source of infection. Ascetic fluid cultures were performed using the conventional culture method and via inoculating $10 \mathrm{ml}$ of fluid in aerobic and anaerobic blood culture bottles at the bedside.

A total number of 100 adult Middle-Eastern Egyptian cirrhotic patients of both sexes were enrolled in this study. 40 patients were excluded from the study (25 patients had hepatocellular carcinoma and 15 patients had severe gastrointestinal bleeding who subsequently died). The remaining 60 patients have ascetic fluid polymorph nuclear cell (PMN) count was lower than $250 \mathrm{~mm} \mathrm{3}$, show no signs or symptoms of peritoneal infection such as severe abdominal pain, fever and chills. They were randomized using stratification method into four groups: Group one or control group (15 patients) who received ciprofloxacin $750 \mathrm{mg} /$ week orally for six months (Ciprobay ${ }^{\mathrm{TM}} 750 \mathrm{mg}$ tablet, Hikma pharma S.A.E under license of Bayer-Schering pharma, Germany), g roup two (15 patients) who received doxycycline $100 \mathrm{mg}$ tablet (Vibramycin $^{\mathrm{TM}} 100 \mathrm{mg}$ tablet ,Pfizer, Egypt) twice daily for ten days and then twice weekly for 6 months, group three (15 patients) who were received commiphora mol mol capsule (Mirazid $^{\mathrm{TM}} \quad$ S.G. capsule, Pharco pharmaceuticals company, Egypt) $10 \mathrm{mg} / \mathrm{kg}$ once daily for six days and then $10 \mathrm{mg} / \mathrm{kg}$ twice weekly for six months and group four (15 patients) who received commiphora mol mol and doxycycline combination by the same doses scheduled above for six months. 
Inclusion criteria were patients with cirrhosis and ascites who had history of at least one previous episode of SBP, age $>18$ and $<80$ years old and both sexes. Exclusion criteria included active gastrointestinal bleeding, encephalopathy > grade 2, hepatocarcinoma or other malignancies, patients with any other inflammatory disease, patients on any medications that can affect inflammatory markers assessment and patients allergic to study medications. All patients of the study took propranolol, spironolactone and furosemide for hypertension and ascites respectively. All patients were classified as Child C using Child-Pugh Classification.

Eligible patients gave their written informed consent. After signing a consent form, all individuals included in the study were submitted to physical examination, medical history (past or current illness), demography (age, sex, smoking habits) and measurement of weight. Body weight was measured using Detecto scale (Detecto Company, 203 East Daugherty Street, USA). All patients were submitted to blood sample collection at enrollment (baseline), three and six months after treatment for assessment of liver function, renal function, sodium level, red and white blood cells count, platelet count, hemoglobin value, serum IL-6 level and C-RP concentration.

Patients were followed up closely every month with careful assessment to rule out any complications such as fever, abdominal pain or other symptoms or signs of infection. Study medication was discontinued in the case of recurrent SBP that represents end point of the trial. The drugs used in the study were withdrawn in patients suffering from other complications such as gastrointestinal bleeding or encephalopathy and receiving the standard treatment in each case.

\subsection{Biochemical assays}

\subsubsection{Measurement of inflammatory markers}

Serum interleukin-6 (IL-6) was assayed using Enzyme-Linked Immunosorbent Assay kit (AviBion Human IL-6 ELISA Kit, Orgenium
Laboratories, Finland) [10].Serum CRP was assayed turbidimetrically using fixed-time measurement (Elicta 1.2, Vita Chem Co., Italy) [11].

\subsubsection{Measurement of liver function parameters:}

Serum aspartate aminotransferase (AST) and serum alanine aminotransferase (ALT) were measured spectrophotometrically using kinetic method [12, 13], serum bilirubin level (total and direct) was measured spectrophotometrically using colorimetric (Diazo) method [14], measurement of serum albumin concentration was determined spectrophotometrically using modified bromocresol green colorimetric method [15],prothrombin time was determined by coagulation method [16].

\subsubsection{Measurement of kidney function parameters:}

Blood urea nitrogen was determined spectrophotometrically using enzymatic (fixed rate) UV method with urease and glutamate dehydrogenase [17], serum creatinine concentration was determined spectrophotometrically using buffered kinetic Jaffé reaction without deproteinization method [18], sodium level was determined colorimetrically [19].

\subsubsection{Measurement of hematological parameters:}

The Sysmex ${ }^{\circledR}$ Automated Hematology Analyzer $\mathrm{KX}-21 \mathrm{~N}$ is used for the assay of haemoglobin $(\mathrm{Hb})$, white blood cells (WBCs), red blood cells (RBCs), and platelets (PLTs). (Sysmex Corporation, Kobe 651-0073, Japan).

\section{Statistical analysis}

Minitab release 15, Pine Hall Road, State College, PA, USA was used for statistical analysis of obtained date. Paired t-test was used to assess any significant difference between each group before and after treatment course. Oneway analysis of variance test and two-sample ttest were used to assess any significant 
difference between groups after treatment. Data were presented as the mean \pm S.D and the level of significance was set at $\mathrm{P}<0.05$.

\section{Results}

Demographic data for all patients in the four studied groups are shown in Table 1 that showed non significant variation between them. Table 2 showed also base line date obtained for measuring parameters for all studied groups and did not show any significant difference; therefore any changes happened after treatment was attributed to the used medications and not due to the individual variations. Laboratory data for patients in the four studied groups three and six months after treatment were demonstrated in Table 3 and Table 4 respectively .The data obtained for all studied groups showed statistically significant decrease $(p<0.05)$ in IL-6 and CRP levels three and six months after treatment as compared to their baseline data .

Table 1: Demographic data of the participants

\begin{tabular}{|l|l|l|l|l|l|}
\hline Parameters & $\begin{array}{l}\text { Group } \\
\text { (Control) }\end{array}$ & $\begin{array}{l}\text { Group 2 } \\
\text { Doxycycline }\end{array}$ & $\begin{array}{l}\text { Group 3 } \\
\text { Commiphora }\end{array}$ & $\begin{array}{l}\text { Group 4 } \\
\text { Combination }\end{array}$ & $\begin{array}{l}\text { P value } \\
\text { ANOVA test }\end{array}$ \\
\hline Age (years) & $61 \pm 7.63$ & $59.4 \pm 6.75$ & $58.4 \pm 7.51$ & $60.2 \pm 7.31$ & 0.791 \\
\hline Sex (male) & $\begin{array}{l}10 \quad(66.67 \\
\%)\end{array}$ & $13(86.67 \%)$ & $11(73.33 \%)$ & $9(60 \%)$ & 0.428 \\
\hline Weight $(\mathrm{kg})$ & $78.47 \pm 5.88$ & $76.43 \pm 7.357$ & $77.57 \pm 8.27$ & $77.97 \pm 7.31$ & 0.887 \\
\hline Smoking $(\%)$ & $3(20 \%)$ & $2(13.33 \%)$ & $2(13.33 \%)$ & $1(6.67 \%)$ & 0.778 \\
\hline Diabetes (\%) & $1(6.67 \%)$ & $2(13.33 \%)$ & $3(20 \%)$ & $2(13.33 \%)$ & 0.778 \\
\hline
\end{tabular}

$n=15$ for all groups.

Table 2: Laboratory baseline data for SBP patients included in the four studied groups

\begin{tabular}{|l|l|l|l|l|l|}
\hline Parameters & $\begin{array}{l}\text { Group } \\
\text { (Control) }\end{array}$ & $\begin{array}{l}\text { Group 2 } \\
\text { Doxycycline }\end{array}$ & $\begin{array}{l}\text { Group 3 } \\
\text { Commiphora }\end{array}$ & $\begin{array}{l}\text { Group 4 } \\
\text { Combination }\end{array}$ & $\begin{array}{l}\text { P value } \\
\text { ANOVA test }\end{array}$ \\
\hline AST (IU/L) & $77.60 \pm 22.5$ & $76.07 \pm 20.81$ & $75.60 \pm 19.51$ & $74.47 \pm 18.24$ & 0.980 \\
\hline ALT (IU/L) & $67.4 \pm 14.37$ & $64.8 \pm 16.18$ & $64.4 \pm 17.09$ & $59.87 \pm 12.72$ & 0.617 \\
\hline BIL-T (mg/dl) & $2.23 \pm 0.93$ & $1.97 \pm 0.57$ & $2.41 \pm 0.74$ & $2.32 \pm 0.58$ & 0.569 \\
\hline BIL-D (mg/dl) & $1.26 \pm 0.74$ & $1.22 \pm 0.59$ & $1.57 \pm 0.64$ & $1.59 \pm 0.60$ & 0.245 \\
\hline Albumin(g/dl) & $2.12 \pm 0.38$ & $2.05 \pm 0.44$ & $2.21 \pm 0.47$ & $2.20 \pm 0.53$ & 0.756 \\
\hline PT $(\mathrm{Sec})$. & $26.73 \pm 4.95$ & $26.89 \pm 4.28$ & $26.67 \pm 4.77$ & $26.79 \pm 4.54$ & 0.999 \\
\hline BUN $(\mathrm{mg} / \mathrm{dl})$ & $56.93 \pm 17.06$ & $53.27 \pm 16.06$ & $56.07 \pm 21.27$ & $59.4 \pm 17.8$ & 0.827 \\
\hline S.Cr $(\mathrm{mg} / \mathrm{dl})$ & $1.19 \pm 0.59$ & $1.13 \pm 0.46$ & $1.05 \pm 0.51$ & $1.22 \pm 0.74$ & 0.856 \\
\hline Sodium $(\mathrm{mEq} / \mathrm{L})$ & $127.47 \pm 5.49$ & $126.8 \pm 4.31$ & $127.47 \pm 4.76$ & $127.73 \pm 5.44$ & 0.963 \\
\hline Hb $(\mathrm{g} / \mathrm{dl})$ & $10.31 \pm 1.44$ & $10.49 \pm 1.63$ & $10.28 \pm 1.48$ & $10.01 \pm 1.05$ & 0.826 \\
\hline RBC s $(103 / \mu 1)$ & $3.36 \pm 0.76$ & $3.38 \pm 0.66$ & $2.99 \pm 0.59$ & $2.94 \pm 0.44$ & 0.101 \\
\hline WBCs $(103 / \mu 1)$ & $6.58 \pm 1.62$ & $6.17 \pm 1.3$ & $6.04 \pm 1.3$ & $6.21 \pm 1.54$ & 0.771 \\
\hline Platelets $(103 / \mu l)$ & $72.5 \pm 11.76$ & $78.13 \pm 16.24$ & $79.8 \pm 5.8$ & $79.33 \pm 9.90$ & 0.295 \\
\hline IL-6 $(\mathrm{pg} / \mathrm{ml})$ & $189.36 \pm 25.76$ & $187.30 \pm 22.28$ & $185.02 \pm 19.99$ & $185.76 \pm 23.41$ & 0.993 \\
\hline C-RP $(\mathrm{mg} / \mathrm{l})$ & $60.73 \pm 8.69$ & $52.70 \pm 8.71$ & $55.16 \pm 8.95$ & $58.47 \pm 8.74$ & 0.073 \\
\hline
\end{tabular}

Data are presented as mean $\pm \mathrm{SD}, \mathrm{P}<0.05$ is considered significant(ANOVA test)

AST ( Aspartate transaminase); ALT (Alanine-aminotransferase); BIL-T (Total bilirubin); BIL-D ( Direct bilirubin); PT (Prothrombin time); BUN (Blood Urea Nitrogen); S.Cr (Serum creatinine); Hb (Hemoglobin); RBCs (Red blood cells); WBCs (White blood cells); IL-6 (interleukin-6); C-RP (C-Reactive Protein).

$n=15$ for all groups. 
Furthermore, the levels of both IL-6 and CRP six month after treatment were significantly lower than their detected levels three months after treatment $(\mathrm{p}<0.05)$

There is significant decrease in IL-6 and CRP levels three and six months after treatment as compared to their baseline data (paired t- test) $(\mathrm{p}<0.05)$ The change in serum IL-6 and CRP levels within the four studied groups through the study period was demonstrated in Figure 1 and Figure 2 respectively.

There was significant decrease in AlT and AST in group $3 \& 4$ when compared to group $1 \&$ 2 in follow up after $3 \& 6$ months $(\mathrm{p}<0.05)$. As regarding hematological parameters, group 3 showed statistically significant increase in WBCs both three and six months after treatment in comparing to its base line data (paired t- test) $(\mathrm{p}<0.05)$ as shown in Figure 3.

Table 3: Laboratory data for SBP patients included in the four studied groups 3 months after prophylactic therapy

\begin{tabular}{|l|l|l|l|l|l|}
\hline Parameters & $\begin{array}{l}\text { Group } \\
\text { (Control) }\end{array}$ & $\begin{array}{l}\text { Group 2 } \\
\text { Doxycyclin } \\
\text { e }\end{array}$ & $\begin{array}{l}\text { Group 3 } \\
\text { Commiphor } \\
\text { a }\end{array}$ & $\begin{array}{l}\text { Group 4 } \\
\text { Combination }\end{array}$ & $\begin{array}{l}\text { P value } \\
\text { ANOVA test }\end{array}$ \\
\hline AST (IU/L) & $85.7 \pm 14.89$ & $83.8 \pm 10.41$ & $70.47 \pm 13.39$ & $72.60 \pm 14.1$ & 0.005 \\
\hline ALT (IU/L) & $71.67 \pm 10.81$ & $69.60 \pm 11.81$ & $59.60 \pm 9.05$ & $57.60 \pm 10.09$ & 0.001 \\
\hline BIL-T (mg/dl) & $2.41 \pm 0.69$ & $2.18 \pm 0.62$ & $2.22 \pm 0.75$ & $2.44 \pm 0.58$ & 0.569 \\
\hline BIL-D (mg/dl) & $1.54 \pm 0.46$ & $1.37 \pm 0.40$ & $1.45 \pm 0.59$ & $1.65 \pm 0.57$ & 0.476 \\
\hline Albumin(g/dl) & $1.99 \pm 0.50$ & $1.98 \pm 0.40$ & $2.28 \pm 0.45$ & $2.26 \pm 0.44$ & 0.114 \\
\hline PT (Sec.) & $27.15 \pm 3.85$ & $27.79 \pm 3.78$ & $27.89 \pm 3.75$ & $27.69 \pm 3.22$ & 0.926 \\
\hline BUN (mg/dl) & $59.13 \pm 16.15$ & $54.4 \pm 16.32$ & $56.93 \pm 18.85$ & $61.93 \pm 15.5$ & 0.652 \\
\hline S.Cr (mg/dl) & $1.33 \pm 0.39$ & $1.22 \pm 0.32$ & $1.10 \pm 0.41$ & $1.46 \pm 0.42$ & 0.08 \\
\hline $\begin{array}{l}\text { Sodium }(\mathrm{mEq} / \mathrm{L}) \\
\text { Hb }(\mathrm{g} / \mathrm{dl})\end{array}$ & $126.2 \pm 5.47$ & $126.13 \pm 4.26$ & $127.67 \pm 4.50$ & $127.53 \pm 4.91$ & 0.720 \\
\hline $\begin{array}{l}\text { RBCs }(103 / \mu \\
1\end{array}$ & $3.25 \pm 0.65$ & $3.22 \pm 0.60$ & $3.06 \pm 0.51$ & $3.01 \pm 0.3$ & 0.617 \\
\hline $\begin{array}{l}\text { WBCs }(103 / \\
\mu 1)\end{array}$ & $6.41 \pm 1.67$ & $5.91 \pm 1.35$ & $6.47 \pm 1.13$ & $6.37 \pm 1.44$ & 0.521 \\
\hline $\begin{array}{l}\text { Platelets } \\
(103 / \mu l)\end{array}$ & $68.3 \pm 16.77$ & $73.67 \pm 17.62$ & $78.27 \pm 8.05$ & $76.6 \pm 12.92$ & 0.722 \\
\hline $\begin{array}{l}\text { IL-6 (pg/ml) } \\
10.14 \pm 1.37\end{array}$ & $10.22 \pm 1.54$ & $10.71 \pm 1.15$ & $10.3 \pm 0.94$ & 0.257 \\
\hline C-RP (mg/l) & $37.71 \pm 6.05$ & $35.26 \pm 4.37$ & $34 . .37 \pm 8.10$ & $24.78 \pm 6.38$ & 0.000 \\
\hline
\end{tabular}

Data are presented as mean $\pm \mathrm{SD}, \mathrm{P}<0.05$ is considered significant(ANOVA test)

AST ( Aspartate transaminase); ALT (Alanine-aminotransferase); BIL-T (Total bilirubin); BIL-D ( Direct bilirubin); PT (Prothrombin time); BUN (Blood Urea Nitrogen); S.Cr (Serum creatinine); Hb (Hemoglobin); RBCs (Red blood cells); WBCs (White blood cells); IL-6 (interleukin-6); C-RP (C-Reactive Protein).

$n=15$ for all groups. 
Table 4: Laboratory data for SBP patients included in the four studied groups 6 months after prophylactic therapy

\begin{tabular}{|l|l|l|l|l|l|}
\hline Parameters & $\begin{array}{l}\text { Group } \\
\text { (Control) }\end{array}$ & $\begin{array}{l}\text { Group 2 } \\
\text { Doxycycline }\end{array}$ & $\begin{array}{l}\text { Group 3 } \\
\text { Commiphora }\end{array}$ & $\begin{array}{l}\text { Group 4 } \\
\text { Combination }\end{array}$ & $\begin{array}{l}\text { P value } \\
\text { ANOVA test }\end{array}$ \\
\hline AST (IU/L) & $86.87 \pm 16.81$ & $85.33 \pm 11.56$ & $65.33 \pm 16.4$ & $69.2 \pm 10.9$ & 0.000 \\
\hline ALT (IU/L) & $75.33 \pm 16.29$ & $71.2 \pm 12.36$ & $52.67 \pm 14.80$ & $55.73 \pm 10.51$ & 0.000 \\
\hline BIL-T (mg/dl) & $2.56 \pm 0.74$ & $2.21 \pm 0.62$ & $1.99 \pm 0.89$ & $2.54 \pm 0.49$ & 0.087 \\
\hline BIL-D (mg/dl) & $1.74 \pm 0.45$ & $1.55 \pm 0.55$ & $1.24 \pm 0.65$ & $1.75 \pm 0.53$ & 0.210 \\
\hline Albumin(g/dl) & $1.96 \pm 0.50$ & $1.95 \pm 0.46$ & $2.43 \pm 0.63$ & $2.33 \pm 0.46$ & 0.060 \\
\hline PT (Sec.) & $28.46 \pm 4.38$ & $28.33 \pm 3.72$ & $28.75 \pm 3.70$ & $28.76 \pm 3.16$ & 0.986 \\
\hline BUN (mg/dl) & $63.33 \pm 18.2$ & $56.67 \pm 11.2$ & $59.13 \pm 20.25$ & $64.13 \pm 14.28$ & 0.557 \\
\hline S.Cr $(\mathrm{mg} / \mathrm{dl})$ & $1.52 \pm 0.29$ & $1.41 \pm 0.42$ & $1.16 \pm 0.4$ & $1.60 \pm 0.36$ & 0.362 \\
\hline Sodium $(\mathrm{mEq} / \mathrm{L})$ & $125.03 \pm 5.02$ & $125.8 \pm 4.54$ & $127.93 \pm 4.61$ & $127.13 \pm 4.05$ & 0.530 \\
\hline Hb $(\mathrm{g} / \mathrm{dl})$ & $9.96 \pm 1.26$ & $10.15 \pm 1.56$ & $10.81 \pm 0.79$ & $10.39 \pm 1.18$ & 0.267 \\
\hline RBCs $(103 / \mu 1)$ & $3.16 \pm 0.59$ & $3.17 \pm 0.7$ & $3.19 \pm 0.4$ & $3.12 \pm 0.44$ & 0.985 \\
\hline WBCs $(103 / \mu 1)$ & $5.81 \pm 1.8$ & $5.55 \pm 0.9$ & $6.87 \pm 1.25$ & $6.33 \pm 1.32$ & 0.114 \\
\hline Platelets $(103 / \mu l)$ & $64.4 \pm 20.19$ & $72 \pm 21.26$ & $77.13 \pm 12.82$ & $75.8 \pm 14.79$ & 0.205 \\
\hline IL-6 (pg/ml) & $102.82 \pm 13.37$ & $99.32 \pm 13.00$ & $96.41 \pm 18.91$ & $65.95 \pm 11.86$ & 0.000 \\
\hline C-RP $(\mathrm{mg} / \mathrm{l})$ & $25.33 \pm 7.39$ & $22.07 \pm 2.11$ & $21.46 \pm 4.62$ & $14.65 \pm 0.68$ & 0.000 \\
\hline
\end{tabular}

Data are presented as mean $\pm \mathrm{SD}, \mathrm{P}<0.05$ is considered significant(ANOVA test)

AST ( Aspartate transaminase); ALT (Alanine-aminotransferase); BIL-T (Total bilirubin); BIL-D ( Direct bilirubin); PT (Prothrombin time); BUN (Blood Urea Nitrogen); S.Cr (Serum creatinine); Hb (Hemoglobin); RBCs (Red blood cells); WBCs (White blood cells); IL-6 (interleukin-6); C-RP (C-Reactive Protein). $n=15$ for all groups.

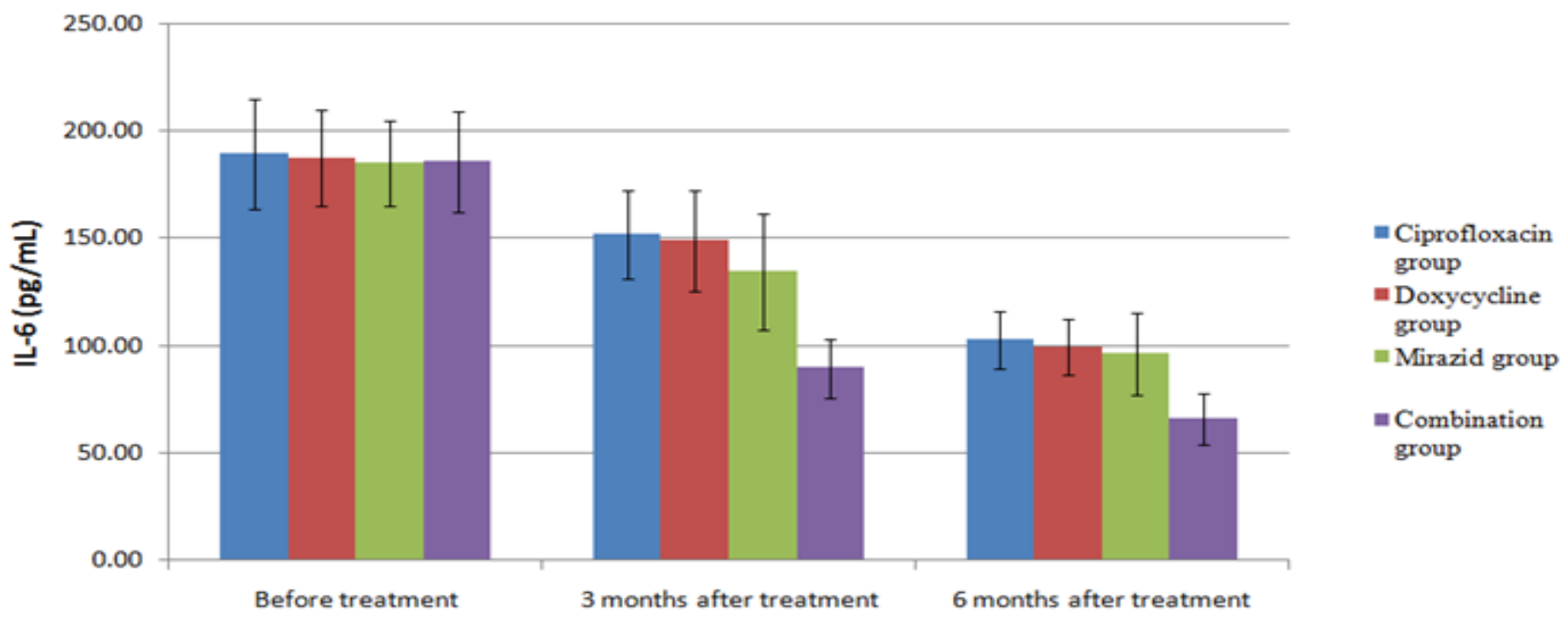

Figure 1. Changes in the level of IL- $6(\mathrm{pg} / \mathrm{ml})$ in the four studied groups before, three and six months after treatment. Data presented by mean \pm SD. IL- 6 level in the four groups decreases significantly $(P<0.05)$ three and six months after treatment in comparison with its baseline level (paired t-test), $\mathrm{n}=15$. 


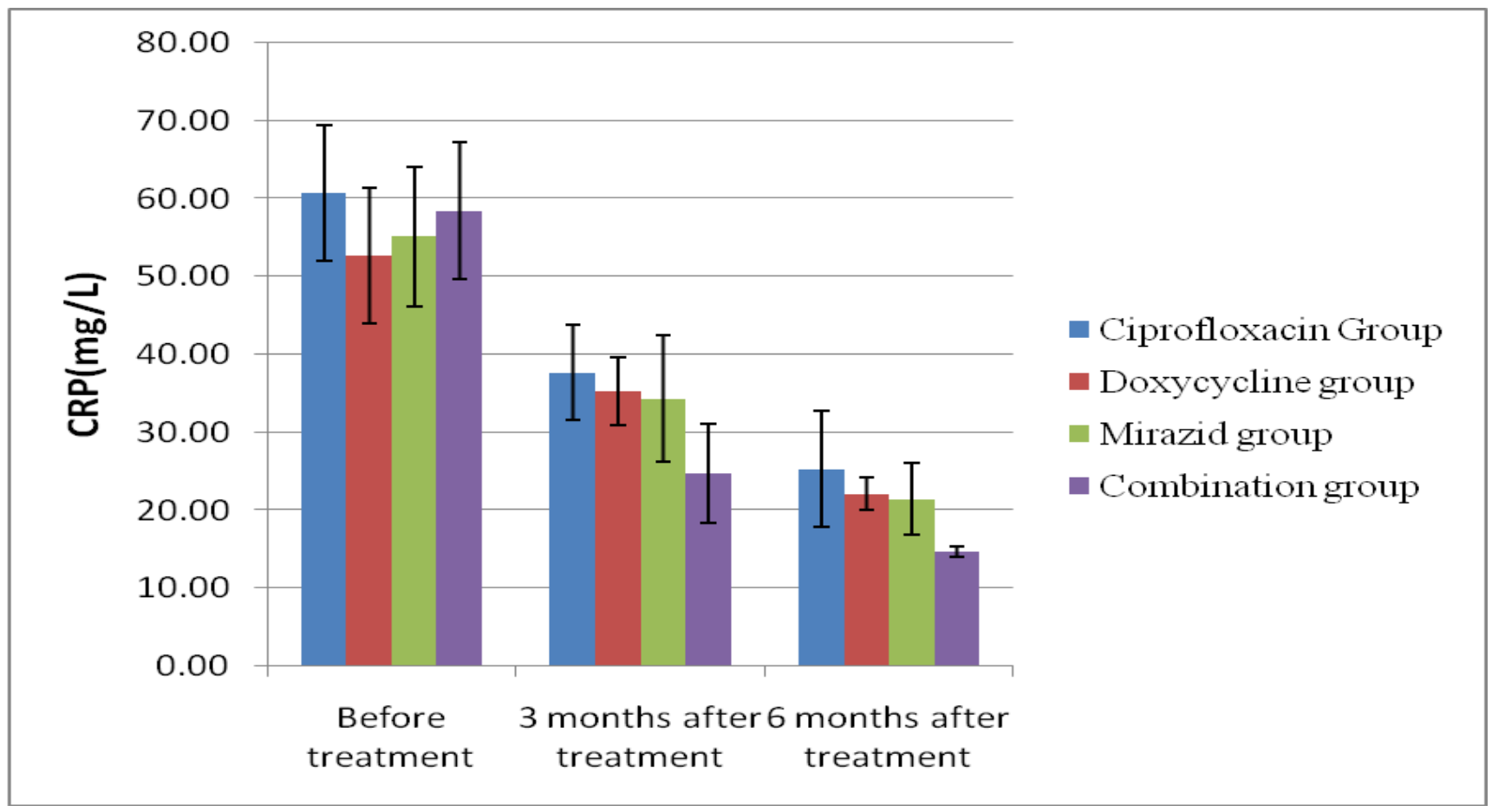

Figure 2. Changes in the level of CRP $(\mathrm{mg} / \mathrm{L})$ in the four studied groups before, three and six months after treatment. Data presented by mean \pm SD. CRP level in the four groups decreases significantly $(P<0.05)$ three and six months after treatment in comparison with its baseline level (paired $t$ test), $n=15$.

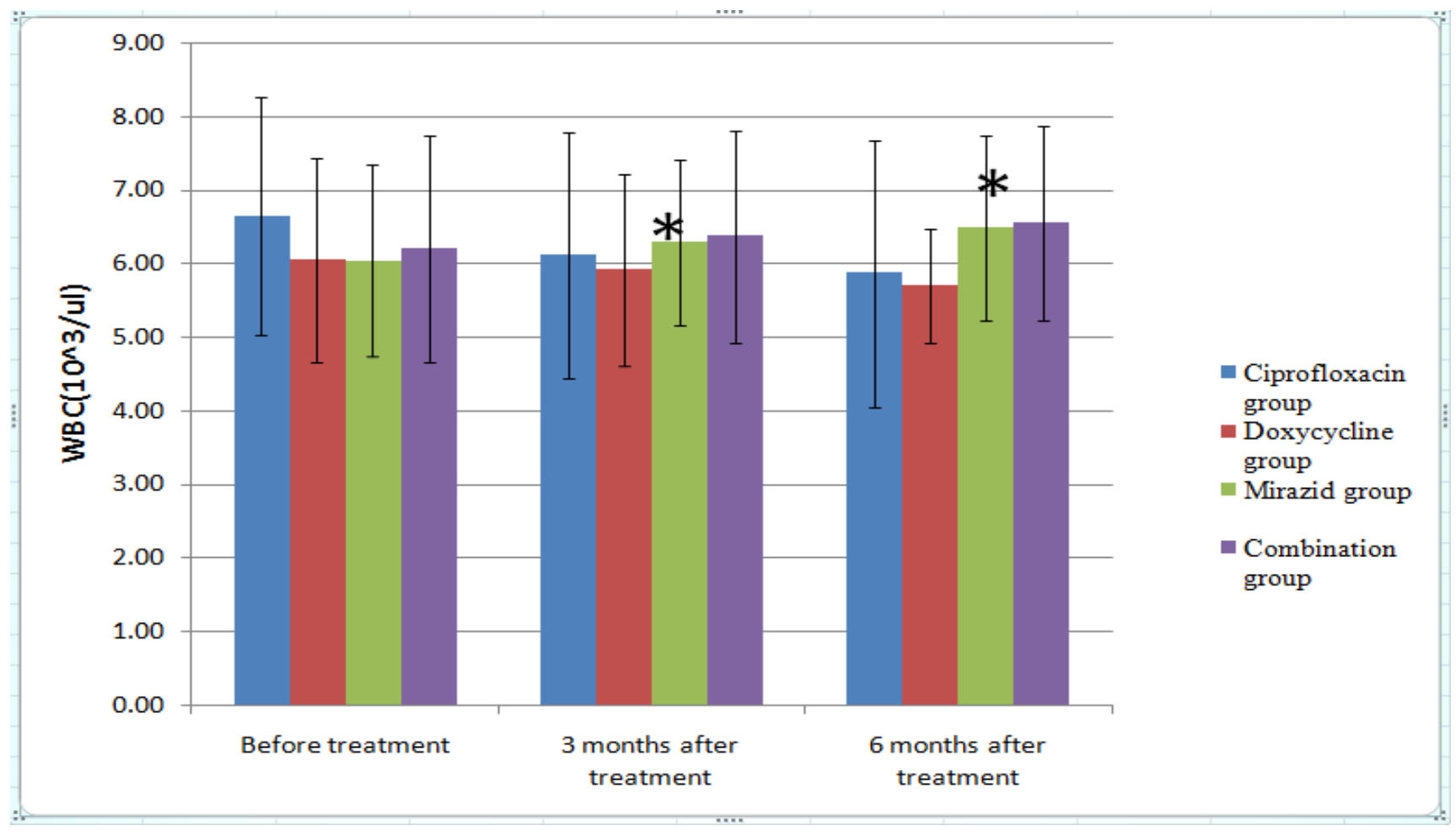

Figure 3. Changes in the level of $\mathrm{WBC}\left(10^{\wedge} 3 / \mathrm{ul}\right)$ in the four studied groups before, three and six months after treatment. Data presented by mean \pm SD. WBC count in the group three decreases significantly $(P<0.05)$ three and six months after treatment in comparison with its baseline level (paired t test), $\mathrm{n}=15$. 


\section{Discussion}

The results of the current study are promising and demonstrate the efficacy of doxycycline and Commiphora molmol as primary prophylactic therapy against SBP. Diagnostic paracentesis remains the gold standard for rapid diagnosis of SBP, its associated risks [20] makes efforts seek for alternative safe tests for diagnosing SBP. The measurement of inflammatory markers such as serum IL-6 and CRP seems to be helpful whereas IL-6 plasma level was found to be the most sensitive and specific tool for the diagnosis of bacterial infection in decompensate cirrhotic patients [21].

IL-6 is a multifunctional cytokine that mediates several acute phase inflammations. IL-6 is produced by some hepatic cells such as kupffer cells and sinusoidal endothelial cells (SEC) which mediate hepatic fibrogenesis [22]. It was found an initial IL-6 level was significantly higher in infected cirrhotics than non-infected cirrhotic patients [23]. In addition, hepatocytes produce CRP in large amounts upon stimulation by the cytokines like IL- 6 and TNF- $\alpha$ during the acute-phase response [24]. It was therefore hypothesized that the use of CRP could be useful in the detection of SBP. It has been suggested that CRP and TNF- $\alpha$ serum levels were significantly higher in patients with SBP comparing to patients with sterile ascites [25].The serum CRP concentration was found to separate patients into infected peritonitis and non-infected categories better than the ascetic fluid CRP concentrations [26]. The previous data justifies our selection of both serum IL-6 and CRP as main parameter to test the efficacy of studied medications. Our study duration was six months which seems acceptable and matches with other findings suggested that six months follow-up period is the required duration to investigate the prophylactic activity of antibiotics against SBP [27].

Group one patients (control group) were received ciprofloxacin $750 \mathrm{mg} /$ week depending on the report of previous studies reported high fecal concentration of ciprofloxacin up to 6 days after a single oral dose and suggested its ability to provide long term prevention of SBP in cirrhotic patients [27]. Group one showed significant decrease in IL-6 level three and six months after ciprofloxacin administration which agreed with reported findings that serum TNF- $\alpha$ and IL-6 levels were reduced significantly 24 and $48 \mathrm{~h}$ after ciprofloxacin treatment [28].

In addition, group one showed significant decrease in CRP level three and six months following ciprofloxacin administration. The overall results indicate that ciprofloxacin may have anti-inflammatory and immunomodulatory effect on SBP patients by attenuating the proinflammatory response independently on its antibacterial effect.

Unfortunately, it has been suggested that the microbial etiology of SBP have been changed with subsequent increased chance of quinolone prophylaxis failure [29]. Thus, we aimed to test another antibiotic (doxycycline) which exerts a broad range of antimicrobial activity against both Gram-positive and Gram-negative bacteria [7.8]. Doxycycline was absorbed very rapidly from the peritoneal cavity and due to its slow excretion, it is used for peritoneal lavage for patients suffering from diffuse peritonitis due to perforated appendicitis [30] suggesting its use as prophylactic agent [31].Dosing schedule for group two was based its long elimination half-life which $(12-25 \mathrm{~h})$ which may be prolonged in patients with liver cirrhosis [32]. Secondly, doxycycline $200 \mathrm{mg} /$ week was formerly used for prophylaxis against leptospirosis [33].

Group two patients showed significant decrease in IL-6 levels three and six months a result compatible with previously study demonstrated that treatment with doxycycline resulted in a significant decline in cytokine levels (IL-6 and TNF- $\alpha$ ) in patients with scrub typhus [34]. Furthermore, Group two showed significant decrease in CRP level which seems parallel with other studies investigated that sub antimicrobial doses of doxycycline could significantly reduce serum CRP and serum IL-6 levels in patients with coronary artery disease and in postmenopausal women with chronic periodontitis [35].

An alternative therapy to guard against antibiotic resistance is the implication of medicinal plants that provide many advantages 
such as fewer side effects, good patient tolerance and less cost. Group three dosing scedule based on its approved dose as anti schistosomal agent in Egypt [36]. This approved dose appears to be safe, effective, non hepatotoxic and noncarcinogenic dose [37]. Furthermore, we aimed to test the use of Commiphora molmol as prophylactic therapy depending on the reports of previous studies demonstrated its antifungal and antibacterial activities against some microbes that implicated in SBP episodes [38].In addition it has antibacterial and antifungal activity against standard pathogenic strains of Escherichia coli, Staphylococcus aureus, Pseudomonas aeruginosa and Candida albicans that considered predisposing agent for SBP due to sesquiterpenes derived from myrrh or Commiphora mol mol extract (furanodiene-6-one and methoxyfuranoguaia-9-ene-8-one) $\quad[37,39]$.The petroleum ether extract of myrrh was also found effective as anti-inflammatory activity [40]. Also, it was found that the crude resin of C. molmol has anti-inflammatory activity $[41,42]$.

Group 3 patients showed significant decrease in IL-6 and CRP levels three and six months after using Commiphora mol mol. Our findings are in accordance with results from other studies where there was a significant reduction of IL-1betastimulated IL-6 and IL-8 production by fibroblasts treated with myrrh [43].Moreover, IL6 and CRP levels were decreased in hyperlipidemic subjects on myrrh [44]. Additionally, it has been demonstrated that, Commiphora species have anti-inflammatory effects through suppression of many cytokines (IL-12, IL-6, TNF- $\alpha$ and IL-1 $\beta$ ) in serum, liver and peritoneal fluids [45].It was found that, pretreatment of myrrh inhibited LPS-induced production of proinflammatory cytokines, NO, and PGE2 in peritoneal macrophages. In addition, myrrh inhibited CLP-induced production of IL$1 \beta$, IL-6, and TNF- $\alpha$ in mice serum and liver. These results suggest that myrrh may have antiinflammatory properties [46].

However, the effects and the mechanisms underlying anti-inflammatory activities of myrrh are poorly defined. I suggest some expectations for explanation of anti-inflammatory mechanism of myrrh .In inflammatory processes, macrophages are important players providing immediate defense against foreign agents. Upon activation, macrophages produce excess inflammatory mediators, such as tumor necrosis factor- $\alpha$ (TNF- $\alpha$ ), interleukin (IL), leukotrienes, nitric oxide (NO), and prostaglandin E2 (PGE2) [47, 48]. Thus, inhibition of inflammatory responses is an important target in the treatment of inflammatory diseases.

First, myrrh might inhibit the production of NO through suppression of iNOS (inducible nitric oxide synthase), expression which is an important regulatory molecule in a range of physiological and pathological processes [49].

Secondly, myrrh may inhibit the production of PGE2 (key inflammatory mediator) through the suppression of COX-2 expression [50].

Thirdly, myrrh might inhibit production of NO, PGE2, IL-6 and TNF- $\alpha$ through the inhibition of the JNK (c-Jun N-terminal kinases) pathway which regulate various cellular activities including signal transduction and expression of proinflammatory [51].

Therefore, it is likely that Myrrh exerted an anti-inflammatory effect in vivo by increasing bacterial clearance and inhibiting proinflammatory cytokines production such as IL-1 $\beta$, IL- 6 , and TNF- $\alpha$.From all the above, its is clear that Commiphora mol molcan be used in prophylaxis of SBP due to dual action, its antibacterial and anti-inflammatory activities.

On the other hand, both three and six months after Commiphora mol mol intake, we reported a statistically significant increase in WBCs. This increase in white blood cells count may be attributed to an elevated rate of myrrh- antigendriven leukocytes proliferation [52].

Following three and six months of treatment course, there was a statistically significant decrease in AST and ALT levels in group three and group four when compared to group one and group two $(\mathrm{p}<0.05)$. This can be explained as group one and group two administrated ciprofloxacin and doxycycline respectively cause serum enzyme elevations during therapy which considered an adverse effect [53,54].

Group three and group four administrated commiphora mol mol alone or in combination with doxycycline respectively provides many 
advantages such as fewer side effects safe, effective and non-hepatotoxic [37]. Clinical study of using mirazid in patients with compensated hepatosplenic schistosomiasis or schistosomal colitis alone showed that liver function tests exhibited a significant improvement with regard to the levels of liver enzymes [55].

Group four showed significant decrease in IL-6 and CRP levels three and six months after therapy. Furthermore, group four showed significantly lower IL-6 and CRP levels as compared to the other studied groups. This result may be attributed to the synergistic effect between Commiphora molmol and doxycycline. It has been reported that, the crude extract of the oleo-resin of Commiphora molmol displayed potentiation of tetracycline effect against against S. aureus, several Salmonella enterica, Typhimurium strains and two Klebsiella pneumonia strains [56]. Furthermore, it was reported that, the implication of Commiphora molmol with tetracycline resulted in synergetic interaction against Gram positive bacteria (Staphylococcus aureus and Bacillus megaterium) and Gram negative bacteria (E. coli, Pseudomonas aeruginosa and K. pneumonia) [57]. This synergistic effect may be attributed to the ability of Commiphora molmol to significantly increase the Post Antibiotic Effect (PAE) of tetracycline by extending the lifetime of fading antibiotics [57]. The above mentioned information may give logical justification for our result obtained with Commiphora mol $\mathrm{mol} /$ doxycycline combination. The limitation of our study includes the relatively small numbers of patients investigated. In terms of a clinical application, larger controlled clinical trials are needed to establish the impact of such therapies on outcomes for patients.

\section{Conclusion}

To our knowledge, this study is the first clinical trial aimed to evaluate the outcome of implication of doxycycline, Commiphora molmol and their combination as prophylactic therapy against SBP. The results of the current study are promising and demonstrate the efficacy of doxycycline and Commiphora molmol as primary prophylactic therapy against SBP. Furthermore, commiphora mol mol /doxycycline combination was the most effect and showed additive effect which may be useful in decrease emergence of resistant strains. Consequently we are recommending doxycycline and commiphora mol mol as alternative prophylactic therapy for ciprofloxacin failure in patients with SBP.

\section{Authors' contributions}

Tarek Mostafa and Eman Elberri designed the study, performed the statistical analysis, wrote the protocol, and wrote the first draft of the manuscript. Osama Ibrahim managed the analyses of the study. Gamal Badra managed the literature search.All authors read and approved the final manuscript.

\section{Compliance with Ethical Standards}

- Tarek mostafa, Osama ibrahim, Gamal badra and Eman elberri declare that they have no conflict of interest.

- Ethical approval: The protocol for this study was approved by the National Research Ethics Committee of Menoufiya University, Shebin El-kom,Egypt with Institutional Review Board (IRB) protocol number 0064/2012.

- Informed consent: Informed consent was obtained from all individual participants included in the study.

\section{Acknowledgement}

The Authors sincerely appreciate the doctors of National Liver Institute at Menoufiya University for allowing their patients to participate in this study, for their aid in participants' selection, diagnosis and for their valuable recommendations all over this study. Also, we appreciate Clinical Pharmacy Department Research Center for the financial support. We are so grateful for patients who participated in our study without them the study would not have been a success. 
References

1. Ozmen S, Dursun M, Yilmaz S. Spontaneous bacterial peritonitis: pathogenesis, diagnosis, and management. Acta Gastroenterol Belg. 2006; 69(3):276-282.

2. Fernández J, Navasa M, Gómez J, Colmenero J, Vila J, Arroyo V, Rodés J. Bacterial infections in cirrhosis: epidemiological changes with invasive procedures and norfloxacin prophylaxis. Hepatology. 2002; 35(1):140-148.

DOI: $10.1053 /$ ihep.2002.30082

3. Strauss E, Caly WR. Spontaneous bacterial peritonitis: a therapeutic update. Expert Rev Anti Infect Ther. 2006; 4(2):249-260. DOI:10.1586/14787210.4.2.249

4. Pleguezuelo M, Benitez JM, Jurado J, Montero JL, De la Mata M. Diagnosis and management of bacterial infections in decompensated cirrhosis.World J Hepatol. 2013;5(1):16-25.

DOI:10.4254/wjh.v5.i1.16.

5. Saab S, Hernandez JC, Chi AC, Tong MJ. Oral antibiotic prophylaxis reduces spontaneo us bacterial peritonitis occurrence and improv es short-termsurvival in cirrhosis: a metaanalysis. Am J Gastroenterol. 2009; 104(4):993-1001. DOi:10.1038/ajg.2009.3

6. Runyon B.A.Management of adult patients with ascites due to cirrhosis: an update. Hepatology, 2009; 49(6):2087-2107. DOI: $10.1002 /$ hep. 22853

7. Luis ML, Alora BD., LaO LM, Mendoza T L., Guevara R., Alora AT. Doxycycline in the Treatment of Respiratory and Urinary Tract Infections. Philladeliphia journal of Microbiology and Infective Disease, 1973; 2(1), 46-50.

8. Mustafa G. , Tolga A, Habeoğlu MA. Spontaneous bacterial peritonitis related to Brucella infection in a cirrhotic patient .European Journal of General Medicine, Eur J Gen Med 2007; 4(4):201-204.

9. Rashida B., Elmorshedy H., Alan F. Efficacy of Myrrh In the treatment of human Schistosomiasis Mansoni. The
American journal of tropical medicine and hygiene, 2005; 73(2):365-367.

10. Mesri $M$ and Altieri D. Endothelial cell activation by leukocyte microparticles. J. Immunol. 1998; 161: 4382-4387.

11. Otsuji S, Shibata H, Umeda M. Turbidimetric immunoassay of serum C-reactive protein. ClinChem. 1982; 28: 2121-2124.

12. Bergmeyer HU, Hørder M, Rej R. International Federation of Clinical Chemistry (IFCC) Scientific Committee, Analytical Section: approvedrecommendation (1985) on IFCC methods for the measurement of catalytic concentration of enzymes. Part 2.IFCC method for aspartate aminotransferase (L-aspartate: 2-oxoglutarate aminotransferase, EC 2.6.1.1). J Clin Chem Clin Biochem. 1986; 24(7):497-510.

13. Bergmeyer HU, Hørder M, Rej R. International Federation of Clinical Chemistry (IFCC) Scientific Committee, Analytical Section: approvedrecommendation (1985) on IFCC methods for the measurement of catalytic concentration of enzymes. Part 3.IFCC method for alanine aminotransferase (L-alanine: 2-oxoglutarate aminotransferase, EC 2.6.1.2). J Clin Chem Clin Biochem. 1986; 24(7):481-495.

14. Doumas BT, Kwok-Cheung PP, Perry BW, Jendrzejczak B, McComb RB, Schaffer R, HauseLL.Candidate reference method for determination of total bilirubin in serum: development and validation. Clin Chem. 1985; 31(11):1779-1789.

15. Doumas BT, Watson WA, Biggs HG. Albumin standards and the measurement of serum albumin with bromcresol green. Clin Chim Acta. 1971; 31(1):87-96. DOI:10.1016/0009-8981(71)90365-2

16. Quick A. J. Quick on "Quick agglutination venostasis" bleeding time technique. Journal of Laboratory and Clinical Medicine, 1973; 26:1812.DOI: 10.1177/000456329202900301

17. Taylor AJ, Vadgama P. Analytical reviews in clinical biochemistry: the estimation of urea. Ann Clin Biochem. 1992; 29 (Pt 3):245-264. DOI: $10.1177 / 000456328602300101$ 
18. Spencer K. Analytical reviews in clinical biochemistry: the estimation of creatinine. Ann Clin Biochem. 1986; 23 (Pt 1):1-25.

19. Henry RF, Cannon DC, Winklemen JK. Clinical Chemistry Principles and Technics. $2^{\text {nd }}$ Ed, Hargersein, M.D. Harper and Row, 1974.

20. Rimola A, García-Tsao G, Navasa M, Piddock LJ, Planas R, Bernard B, Inadomi JM. Diagnosis, treatment and prophylaxis of spontaneous bacterial peritonitis: a consensus document. International Ascites Club. J Hepatol. 2000;32(1):142-153. DOI:10.1016/S0168-8278(00)80201-9

21. Rodríguez-Ramos C, Galan F, Díaz F, Elvira J, Martín-Herrera L, Girón-González JA. Expression of proinflammatory cytokines and their inhibitors during the course of spontaneous bacterialperitonitis. Dig Dis Sci. 2001;46(8):1668-1676. DOI: 10.1023/A:1010645302750

22. Kojima Y, Suzuki S, Tsuchiya Y, Konno H, Baba S, Nakamura S. Regulation of proinflammatory and anti-inflammatory cytokine responses by Kupffer cells in endotoxinenhanced reperfusion injury after total hepatic ischemia. Transpl Int. 2003; 16(4):231-240. DOI: 10.1111/j.1432-2277.2003.tb00293.x

23. Le Moine $\mathrm{O}$, Devière J, Devaster JM, Crusiaux A, Durand F, Bernuau J, Goldman M, Benhamou JP. Interleukin-6: an early marker of bacterial infection in decompensated cirrhosis. J Hepatol. 1994; 20(6):819-824. DOI: $10.1111 / \mathrm{j} .1432-$ 2277.2003.tb00293.x

24. Vermeire S, Van Assche G, Rutgeerts P. The role of C-reactive protein as an inflammatory marker in gastrointestinal diseases. Nat Clin Pract Gastroenterol Hepatol. 2005 Dec; 2(12):580-586. DOI:10.1038/ncpgasthep0359

25. Sahar SZ, Salwa ME, Samia A, Aziza K, Omar S, Hasnaa SM , Helmy ME, Mohamed F..The Values of Serum and Ascetic Fluid Tumor Necrosis Factor-Alpha (TNF- alpha), TNF-Receptor 1 and C-Reactive Protein (CRP) in Patients with Cirrhotic Ascites. The Egyptian Journal of Hospital Medicine, 2010; 41: $491-501$.
26. Yildirim $\quad B$, Sari $\quad$ R, Isci $\quad N$.

Patients with spontaneous bacterial peritonitis , and malignant and cirrhotic ascites. J Natl Med Assoc. 2005;97(2):276-280.

27. Rolachon A, Cordier L, Bacq Y, Nousbaum JB, Franza A, Paris JC, Fratte S, Bohn B, Kitmacher P, Stahl JP, et al. Ciprofloxacin and long-term prevention of spontaneous bacterial peritonitis: results of a prospective controlledtrial. Hepatology. 1995; 22(4 Pt 1):1171-1174.

28. Gogos CA, Skoutelis A, Lekkou A, Drosou E, Starakis I, Marangos MN, Bassaris HP. Comparative effects of ciprofloxacin and ceft azidime on cytokine production in patients wi th severe sepsiscaused by gram-negative bacteria. Antimicrob Agents Chemother. 2004; 48(8):2793-2798. DOI: 10.1128/AAC.48.8.2793-2798.2004

29. MacDougall C, Powell JP, Johnson CK, Edmond MB, Polk RE. Hospital and community fluoroquinolone use and resistance in Staphylococcus aureus and Escherichia coli in17 US hospitals. Clin Infect Dis. 2005; 41(4):435-440. DOI: $10.1086 / 432056$

30. Wetterfors J, Höjer H. Systemic prophylaxis with doxycycline in surgery of the colon and rectum. Scand J Infect Dis Suppl. 1976 ;(9):94-99.

31. Giercksky KE, Fuglesang J, Christiansen E, Johnson JA, Bergan T. Short term chemotherapeutic prophylaxis in gastrointestinal operations. Surg Gynecol Obstet. 1980; 151(3):349-352.

32. Amarapurkar DN. Prescribing medications in patients with decompensated liver cirrhosis. Int J Hepatol. 2011; 2011:1-5. DOI:10.4061/2011/519526

33. Sehgal SC, Sugunan AP, Murhekar MV, Sharma S, Vijayachari P. Randomized controlled trial of doxycycline prophylaxis against leptospirosis in an endemic area. Int $\mathbf{J}$ Antimicrob Agents. 2000;13(4):249-255. DOI.org/10.1016/S0924-8579(99)00134-X

34. KrakauerT, BuckleyM.Doxycycline is antiinflammatory and inhibits staphylococcal exotoxin-induced cytokines and chemokines. Antimicrob Agents Chemother. 2003; 
47(11):3630-3633.

DOI: 10.1128/AAC.47.11.3630-3633.2003

35. KoppikarRS, AgrawalSV.The effect of subantimicrobial dose-doxycycline periodontal therapy on serum inflammatory biomarker Creactive protein levels in post-menopausal Women: A 2-year, double-blinded, randomized clinical trial. Contemp Clin Dent. 2013; 4(1):71-73. DOI: 10.4103/0976237X.111628

36. OmarA, ElmesallamyGel-S, EassaS. Comparative study of the hepatotoxic, genotoxic and carcinogenic effects of praziquantel distocide \& the naturalmyrrh extract Mirazid on adult male albino rats. J Egypt Soc Parasitol. 2005; 35(1):313-329.

37. Dolara P., Corte B., Ghelardini C, Pugliese AM, Cerbai ., Menichetti S, A. Lo Nostro. Local anaesthetic, antibacterial and antifungal properties of sesquiterpenes from myrrh. Planta MedIca, 2000; 66(4):356-358. DOI: 10.1055/s-2000-8532

38. Emad MA, Amna SK, Nazlina I. Antibacterial activity of oleo-gum resins of Commiphora molmol and Boswellia papyrifera against methicillin resistant Staphylococcus aureus (MRSA).Scientific Research and Essay,2009 ; 4(4) :351-356.

39. Omer SA, Adam SEI and Mohammed OB. Antimicrobial Activity of Commiphora myrrha Against Some Bacteria and Candida albicans Isolated from Gazelles at King Khalid Wildlife Research Centre Research. Journal of Medicinal Plant. 2011; 5(1): 65-71. DOI:10.3923/rjmp.2011.65.71

40. Tariq M, Ageel AM, Al-Yahya MA, Mossa JS, Al-Said MS and Parmar NS. Antiinflammatory activity of Commiphora molmol.Agents Actions.1986; 17(3-4):381382. DOI: $10.1007 / \mathrm{BF} 01982655$

41. Duwiejua M, Zeitlin IJ, Waterman PG, Chapman J, Mhango GJ and Provan GJ. Anti-inflammatory activity of resins from some species of the plant family Burseraceae.Planta Med. 1993; 59(1):12-16. DOI: 10.1055/s-2006-959594

42. Shalaby MA and Hammouda AA. Analgesic, Anti-inflammatory and Antihyperlipidemic Activities of Commiphora molmol Extract
(Myrrh) J Intercult Ethnopharmacol. 2014; 3(2):56-62.

DOI:10.5455/jice.20140130015014

43. Tipton DA, Lyle B, Babich H, Dabbous MKh. In vitro cytotoxic and antiinflammatory effects of myrrh oil on human gingival fibroblasts and epithelial cells. Toxicol in Vitro. 2003; 17(3):301-10.

44. Szapary PO, Wolfe ML, Bloedon LT, Cucchiara AJ, DerMarderosian AH, Cirigliano MD, Rader DJ. Guggulipid for the treatment of hypercholesterolemia: a randomized controlled trial. JAMA. 2003; 290(6):765-772.

Doi:10.1001/jama.290.6.765

45. Manjula N, Gayathri B, Vinaykumar KS, Shankernarayanan NP, Vishwakarma RA, Balakrishnan A. Inhibition of MAP kinases by crude extract and pure compound isolated from Commiphora mukul leads to down regulation of TNF-alpha, IL-1beta and IL-2. Int Immunopharmacol. 2006; 6(2):122-132.

DOI:101016/j.intimp.2005.07.001

46. Kim MS, Bae GS, Park KC, Koo BS, Kim BJ, Lee HJ, Seo SW, Shin YK, Jung WS, Cho JH, Kim YC, Kim TH, Song HJ, Park SJ. Myrrh inhibits LPS-induced inflammatory response and protects from cecal ligation and puncture-inducedsepsis. Evid Based Complement Alternat Med. 2012; 2012:1-11.

47. Guha M. and Mackman N. LPS induction of gene expression in human monocytes. Cellular Signalling, 2001; 13(2):85-94. DOI:10.1016/S0898-6568(00)00149-2

48. Kubes P. and McCafferty D. M. Nitric oxide and intestinal inflammation.American Journal of Medicine 2000; 109(2):150-158. DOI.org/10.1016/S0002-9343(00)00480-0

49. Nathan C.and Xie Q.W.Regulation of biosynthesis of nitric oxide. Journal of Biological Chemistry, 1994; 269(19):1372513728.

50. Smith W. L., Marnett L. J. and DeWitt D. $\begin{aligned} & \text { L.Prostaglandin } \\ & \text { biosynthesis," and thromboxane } \\ & \text { Pharmacology and }\end{aligned}$
Therapeutics, 1991; 49(3) :153-179.
DOI:10.1016/0163-7258(91)90054-P 
51. Celec P.Nuclear factor kappa B-molecular biomedicine: the next generation. Biomedicine and Pharmacotherapy, 2004; 58(6-7):365-371. DOI: 10.4236/ojmip. 2015.51002

52. HafforAS.Effect of Commiphora molmol on leukocytes proliferation in relation to histological alterations before and duringhealing from injury. Saudi J Biol Sci. 2010; 17(2):139-146.

DOI: 10.1016/j.sjbs.2010.02.007.

53. Alcalde M, Donoso MS, Carcfa-Diaz M, Pascasio JM, Narvaez I. Liver disfunction due to ciprofloxacin. Acta Gastroenterol Belg. 1995; 58(5-6):475-476.

54. Björnsson E, Lindberg J, Olsson R. Cholestatic hepatitis attributed to doxycycline therapy. Scand J Gastroenterol, 1997; 32,390395. DOI:10.3109/00365529709007690
55. Sheir Z, Nasr AA, Massoud A, Salama O, Badra GA, El-Shennawy H, Hassan N, Hammad SM. A safe, effective, herbal antischistosomal therapy derived from myrrh. Am J Trop Med Hyg. 2001; 65(6):700-704.

56. Rahman MM, Garvey M, Piddock LJ, Gibbons S. Antibacterial terpenes from the oleo-resin of Commiphora molmol (Engl.). Phytother Res. 2008; 22(10):1356-1360. DOI: $10.1002 /$ ptr.2501

57. Hussin WA and El-Sayed WM. Synergic Interactions between Selected Botanical Extracts and Tetracycline against Gram Positive and Gram Negative Bacteria. Journal of Biological Sciences, 2011; 11:433-441. DOI:10.3923/jbs.2011.433.441 